\title{
Intention to Change Dietary Habits, and Weight Loss Among Norwegian-Pakistani Women Participating in a Culturally Adapted Intervention
}

\author{
M. K. Råberg Kjøllesdal • V. T. Hjellset • \\ B. Bjørge • G. Holmboe-Ottesen $\cdot$ M. Wandel
}

Published online: 17 November 2010

(C) The Author(s) 2010. This article is published with open access at Springerlink.com

\begin{abstract}
The aim was to explore the relationships between degree of participation in a culturally adapted lifestyle intervention and stages of change for healthy eating and weight loss among Pakistani immigrant women in Norway. The intervention lasted 7 months and included 198 women, randomized into control and intervention groups. The odds of losing weight from baseline to followup, and being in action stages of change (compared to preaction stages) with regard to intake of amount and type of fat, sugar and white flour at follow-up, increased significantly with number of group sessions attended. Those in action stage of reducing intake of fat and increasing intake of vegetables, as well as of reducing weight, were significantly more likely than others to have experienced weight loss at follow-up. Participation in the culturally adapted intervention was related to increase in intentions to change dietary behaviours and to weight loss.
\end{abstract}

Keywords Stages of change - Immigrants ·

Dietary habits · Intervention

M. K. Råberg Kjøllesdal $(\bowtie) \cdot$ B. Bjørge $\cdot$ M. Wandel

Department of Nutrition, Institute for Basic Medical Sciences, University of Oslo, Pb 1046, Blindern, 0316 Oslo, Norway

e-mail: m.k.raberg@medisin.uio.no

V. T. Hjellset · G. Holmboe-Ottesen

Department of General Practice and Community Medicine, Institute of Health and Society, University of Oslo, $\mathrm{Pb} 1130$, Blindern, 0318 Oslo, Norway

\section{Introduction}

Background

Many South Asian immigrants in Western countries suffer from overweight $[1,2]$ and related diseases, such as type 2 diabetes (T2D) and cardiovascular diseases (CVD) [3-7]. Several studies have shown that moving from a developing to a Western country is associated with weight gain, and so is length of stay in the new country [8-10]. This weight gain may be due to changes in diet and physical activity, and other effects of migration, such as stress, culture shock and loneliness [11, 12]. Due to cultural and linguistic barriers, recommendations to promote healthy weight in the host population may not reach the immigrants. The immigrants may also have missed similar advice in their country of origin [13].

Culturally adapted efforts in health promotion take into account language, culture and health beliefs. Such efforts have shown positive effects on clinical and behavioural outcomes related to diabetes among Hispanics in the US [14]. Culturally adapted interventions with regard to T2D and CVD, which have been undertaken among South Asians in the UK and Australia, all led to some improvements, either in knowledge, attitudes and practice or in blood pressure and total cholesterol [15-19]. To our knowledge, none of them has focused on the impact on weight reduction.

Stages of Change

The process of change, which involves giving up long established patterns of behaviour, is often complex and occurs over time. The Transtheoretical Model includes the construct of stages of change, which identifies where in the 
temporal process of change a person is [20]. The stages of change are 'precontemplation' (no intention to change in foreseeable future), 'contemplation' (intending to change, but not soon), 'preparation' (intending to change soon), 'action' (recent change) and 'maintenance' (maintaining change over a period of time). Several studies have been exploring the association between stages of change regarding dietary habits, showing that those at higher stages tend to have more favourable dietary habits [21-24]. However, studies using the Trans Theoretical Model are seldom applied to immigrants from non-Western countries. One exception is the Khush Dil study among South Asians in the UK, which showed an increased proportion in the action stage in relation to CHD and diabetes control after a 6 months intervention [25].

\section{Aim}

In Norway, Pakistanis constitute one of the largest immigrant groups, counting about 30,000 persons. They are also among the groups at highest risk of obesity and T2D, with women at an even higher risk than men [1, 2]. A nondirective culturally adapted intervention focusing on lifestyle factors, such as diet and physical activity, among Pakistani immigrant women has been carried out in Oslo, Norway. The main aim of the intervention was to reduce risk factors for T2D. An upward move from pre-action to action stages of change regarding type and amount of fat, sugar and white flour has previously been reported in the intervention group during the intervention, as well as actual dietary changes including reduced intake of soft- and fruit drinks with added sugar and red meat, increased intake of vegetables, fruit and fruit juice and change in type of fat [26]. In this paper, we explore whether degree of participation in the intervention was related to stages of change for healthy eating and weight reduction at follow-up, and whether these intentions were related to actual weight loss during the intervention.

\section{Methods}

\section{Design and Participants}

The intervention study was carried out in 2006-2008 in a suburban area of Oslo (Søndre Nordstrand), having the highest proportion of Pakistani immigrants (12\%) in the city. Based on experience from working with South Asian populations, it has been recommended to use a multirecruitment strategy and follow certain strategies for recruitment, which has been used in the present study: define the demographic and social profiles of the population to be included, consult representative community members to provide assistance in the study, and set eligibility criteria as wide as possible [27]. The recruitment strategy included visits to mosques and other gatherings in the local community and word of mouth. The women were contacted by phone and given a verbal invitation to participate in the project. Since many women in this group have a low level of literacy, oral information is much more comprehensive and reaches a larger part of the population. A Punjabi-speaking research assistant was in charge of the recruitment. She also stayed in touch with the women throughout the intervention, reminding them of the scheduled sessions.

The eligibility criteria were: women living in Norway and born in Pakistan or women born in Norway by two Pakistani parents, 25 years or older. Two hundred and forty five women were invited to the study. Of these, 47 were not included due to self-reported known T2D, close relative already in the project (this to limit the possibility of contamination of effects between control and intervention group, as many live in households with extended families), pregnancy, heart disease, not fitting the eligibility criteria, lack of interest or other reasons. The 198 included women were randomized to either intervention (101) or control (98) using a computerized block randomization list, set up by the trial statistician. A central telephone randomization system was used and information on which group the participant belonged to was obtained and communicated to the participant after finishing the baseline measurements. Of the 198 women, 157 (82 (81.2\%) in intervention group, $77(79.4 \%)$ in control group) came to the follow-up test and were included in the analyses in the present study.

The intervention group was divided into nine subgroups of 10-12 women, and the women were successively assigned to the groups. Each group had six group sessions, lasting $2 \mathrm{~h}$, during 7 months. The group sessions were held in the local mother and baby health care centre and were led by Norwegian project workers with translation into Punjabi. They were focussed on the importance of diet and physical activity for blood glucose regulation, and aimed at helping the women to incorporate knowledge acquired in the group sessions into their every day lives. The teaching was based on knowledge about Pakistani lifestyle both in Pakistan and Norway. Discussions were encouraged at the end of each section. The participants were encouraged to reduce sugar and other refined carbohydrates, and change to more complex carbohydrates, to eat more vegetables, beans and lentils in line with their traditional diet, and to eat more fatty fish. Fruits were recommended in small amounts. Carbohydrates were the main focus of the teaching. Less attention was given to protein and fat. However, the participants were encouraged to change the type of fat from butter/margarine/vegetable oil to oliveand rapeseed oil, and asked to measure the amount of oil 
used in cooking. In addition, they were given short individual feedback on diet and physical activity, based on their blood tests, after the first group session. The women were offered to take part in walking groups, at day time or in the evening, twice a week. To make it feasible, child care was offered, and walking paths where baby carriages could be brought were chosen. Furthermore, since many Pakistani immigrant women do not have footwear suitable for walking outside all year, good walking shoes were provided by Reebok. The control group did not receive lifestyle advice, but were offered one (short version) group session and shoes after the follow-up tests.

\section{Measures}

Data were collected at baseline (right before randomization and intervention) and at follow-up (right after intervention). Body weight was measured in light clothing, without shoes to the nearest $0.1 \mathrm{~kg}$ (A\&D Personal Precision Scale UC-321 weight, Tokyo). The height was measured to the nearest $0.5 \mathrm{~cm}$ (Personal check $^{\circledR}$ measuring device, KaWe, Germany). Data on intentions to change (foods and weight) were collected through an interview carried out by Punjabi speaking interviewers with the help of a questionnaire. The questionnaire was developed based on previously conducted studies in this population [28-30], as well as an international diabetes intervention study (DE-PLAN) [31]. It was also tested in a pilot study with seven immigrant women (not part of the intervention) and revised on the basis of the results.

Socio-demographic variables [age, years lived in Norway and years of education (both from Pakistan and Norway)] were analysed as continuous variables. Command of Norwegian language was recoded from 5 response categories to a dichotomous variable with 'poor' (quite poorpoor $)=0$ and 'good' (average-very good) $=1$. BMI was calculated from measured height and weight $\left(\mathrm{kg} / \mathrm{m}^{2}\right)$, and divided into 'overweight' (BMI $\geq 25)$ and 'obesity' (BMI $\geq 30$ ). The cut off of $\mathrm{BMI} \geq 27.5$, which indicates high risk of T2D and heart disease for South Asians [32], was also used in this study. A standardized oral glucose tolerance test (OGTT) was performed, i.e. $75 \mathrm{~g}$ glucose in $200 \mathrm{ml}$ water was ingested and blood glucose was determined at time zero (after 12-h fasting) and after $2 \mathrm{~h}$. T2D was defined as by $\mathrm{WHO}$ [33], plasma glucose $\geq 7.0 \mathrm{mmol} / \mathrm{l}$ fasting and/or $\geq 11.1 \mathrm{mmol} / \mathrm{l}$ after OGTT. For logistic regressions, weight change from baseline to follow-up was calculated and recoded to a dichotomous variable where "no change/weight gain' $=0$ and 'weight loss' $=1$. Number of group sessions attended was analysed as a continuous variable, with the control group having the value 0 .

Intentions to reduce weight and to change intake of vegetables, fruit, legumes, sugar, white flour and amount and type of fat, were captured by questions related to the stages of change construct from the Trans Theoretical Model [20]. For each item, there was one question about intention to change behaviour, with five response categories: (1) pre-contemplation: 'I have not changed my behavior for the past 6 months, and I am not planning to do so for the next 6 months'; (2) contemplation: 'I have not changed my behavior for the past 6 months, but I am considering doing so within the next 6 months'; (3) preparation: 'At the moment, I am trying to change my behavior, but not on a regular basis'; (4) action: 'During the past 6 months, I have changed my behavior'; and (5) maintenance: 'I changed my behavior $>6$ months ago'. For use in logistic regression, the answers were recoded into two categories: 'pre-action' (precontemplation to preparation) $=0$ and 'action' (action and maintenance) $=1$. Data on stages of change were collected in order to follow changes in intentions during the intervention, however, the intervention program was not tailored to the participants stage of change at baseline.

\section{Analyses}

The data were analysed using SPSS version 14.02. Data on stages of change, number of group sessions attended and changes in weight were not normally distributed and Chisquare tests with continuity corrections and Mann-Whitney $U$ tests were performed to explore the differences between the control and the intervention group, as well as between the control group and those having attended $\geq 4$ sessions. Kruskal-Wallis tests were performed to explore associations between intentions to change dietary habits and weight at baseline and number of group sessions attended. Logistic regressions were used to explore the relationships between firstly; number of group sessions attended and stages of change for weight reduction and different dietary behaviours, and secondly; stages of change and whether or not they had achieved weight loss. The analyses also included the direct relationship between number of group sessions attended and whether weight loss was achieved or not. In addition, the analyses were carried out after those diagnosed with T2D had been excluded. However, this did not change the results substantially. Thus, these results are not shown.

\section{Ethics}

The study is conducted in full accordance with the ethical principles as per the World Medical Association Declaration of Helsinki. All the participants gave a written consent. The Norwegian Data Inspectorate approved the study and it has been cleared by the Regional Committee for Medical Research Ethics. 


\section{Results}

\section{Characterization of Sample}

Table 1 describes the sample at baseline and the weight change from baseline to follow-up. The women were from 25 to 62 years old, on average $41-42$ years. They had been living in Norway from 0 to 35 years, on average 18-19 years. Half of the women rated their command of Norwegian as (quite) poor and they had from 0 to 19 years of education, about 9 years on average. The BMI in the group ranged from 19.6 to 52.4 and mean BMI was close to 30 . More than half had a $\mathrm{BMI} \geq 27.5$. None of the participants were aware of having diabetes before the intervention, however, T2D was detected at baseline in 13.9 and $12.4 \%$ of the intervention and control group respectively. There were no significant differences in these variables between the two groups. Comparing the women who attended $\geq 4$ group sessions with the other women in the intervention group, there were no significant differences at baseline regarding years in Norway, years of education, BMI or prevalence of diabetes detected. However, those who attended $\geq 4$ group sessions were somewhat older (mean 42 years) than the others (mean 39 years) $(P=0.006$, data not shown).
Degree of Participation and Weight Loss

More than half of the participants in the intervention group attended $\geq 4$ group sessions, whereas $14 \%$ did not come to any of the sessions (Table 1). About half of the participants achieved weight loss during the intervention period, with a slightly higher proportion in the intervention group than in the control group. The average weight change was not significantly different between the control group $(-0.27 \mathrm{~kg})$ and the intervention group $(-0.77 \mathrm{~kg})$. However, the average weight change among those who attended $\geq 4$ group sessions $(-1.18 \mathrm{~kg})$ differed significantly $(P=$ 0.028 ) from the control group. In a logistic regression, the OR for having achieved weight loss was 1.15 (CI 1.001-1.32) for each group session attended. When adjusted for the intentions to change (foods and weight), the association between number of group sessions and achieved weight loss was no longer significant. Weight loss was significantly associated with older age $(P=0.012)$, but no significant associations were found between weight loss and the other socio-demographic variables presented in Table 1. Furthermore, attendance in group sessions and weight loss did not differ significantly between those with and without a diagnosis of T2D.

Table 1 Sample characteristics

Description of the sample, intervention and control group, at baseline, and change in weight from baseline to follow-up

The difference between the intervention and the control group is non-significant for all variables

\begin{tabular}{lll}
\hline & $\begin{array}{l}\text { Intervention }(n=101) \\
(n=82 \text { for change/ } \\
\text { reduction) }\end{array}$ & $\begin{array}{l}\text { Control }(n=97) \\
(n=77 \text { for change/ } \\
\text { reduction })\end{array}$ \\
\hline Age, mean (min, max) & $41(27,62)$ & $42(25,62)$ \\
Years in Norway, mean (min, max) & $18(0,33)$ & $19(2,35)$ \\
Command of Norwegian & & \\
(Quite) poor $(\%)$ & 48.5 & 41.7 \\
Good to very good $(\%)$ & 51.5 & 58.3 \\
Education (years) mean (min, max) & $9(0,19)$ & $9(0,17)$ \\
BMI, mean (min, max) & $29.4(20.5,51.3)$ & $29.8(19.6,52.4)$ \\
Overweight (BMI $\geq 25)(\%)$ & 76.2 & 83.5 \\
Obesity (BMI $\geq 30)(\%)$ & 38.6 & 40.2 \\
T2D \% & 13.9 & 12.4 \\
High risk South Asians $(B M I \geq 27.5)(\%)$ & 59.4 & 62.9 \\
Weight change $(k g)$, mean $(\min , \max )$ & $-0.77(-10.15,4.95)$ & $-0.27(-9.30,4.35)$ \\
Weight loss $(\%$ of women) & 59.0 & 48.7 \\
Number of lessons attended $(\%)$ & & \\
0 & 13.9 & \\
1 & 6.9 & \\
2 & 5.0 & \\
3 & 14.9 & \\
4 & 13.9 & \\
5 & 25.7 & \\
6 & 19.8 & \\
\hline
\end{tabular}


Stages of Change

The participants were asked about their intention to change seven dietary behaviours, as well as weight. Table 2 shows the percentage who reported to be in each stage of change for the different behaviours at baseline. There were no significant differences between the intervention and control group. Table 3 shows the percentage who reported to be in each stage of change for the different behaviours after the intervention. A significantly higher proportion of the control group than the intervention group was in the precontemplation stage for changing type of fat, and eating more vegetables and pulses and less sugar and white flour. There were no significant differences between the groups in the preparation stage. A significantly higher proportion of the intervention group than the control group was in the action stage of all diet related variables, except intention to eat more fruit. A significantly higher proportion in the control group than the intervention group was in the maintenance stage for eating more vegetables and less sugar and white flour.

The relationships between number of group sessions attended, stages of change and weight loss at follow-up, were explored using logistic regressions (Fig. 1). These analyses were adjusted for age. The OR of being in the action stages (action and maintenance) compared to the pre-action stages for changing amount and type of fat and eating less sugar and white flour increased with number of group sessions attended (Fig. 1). However, the five stages of change regarding these intentions at baseline were not significantly related to attendance rate (data not shown). Those in the action stages for changing amount of fat, eating more vegetables and having an intention to change weight at follow-up were more likely than others to have lost weight (Fig. 1). There were no significant associations between number of group sessions attended and being in the action stages for increasing intake of fruit and pulses, and there were no significant associations between being in the action stages for increasing intake of fruit and pulses and weight loss.

\section{Discussion}

The likelihood of losing weight increased with number of group sessions attended. The likelihood of being in action stages of change (compared to pre-action) in regard to intake of amount and type of fat, as well as sugar and white flour at follow-up also increased with number of group sessions. Weight loss was more likely for those in the action stage, compared to the pre-action stage, of reducing intake of fat and increasing intake of vegetables, as well as of reducing weight. Having a diagnosis of T2D did not seem to substantially influence attendance rate, nor the relationships between attendance, intentions and weight loss.

The knowledge about impact of culturally adapted interventions on weight loss and about the use of the stages of change construct among South Asians is scarce. However, large weight losses are in general not often seen after similar interventions [34]. In addition, previous studies have found dietary changes to be more related to stage at follow-up than to the actual change in stage $[35,36]$, and similarities between those in precontemplation and maintenance stages have been found in previous research [23].

Our results suggest that the effect of attending group sessions was mediated through the intentions to change dietary behaviour. That the OR for being in the action stages at follow-up for several dietary changes increased with number of group sessions attended, indicates that

Table 2 Distribution into stages of change at baseline

\begin{tabular}{|c|c|c|c|c|c|c|c|c|c|c|c|c|}
\hline \multirow[b]{2}{*}{ Group } & \multicolumn{2}{|l|}{$N$} & \multicolumn{2}{|c|}{ Precontemplation } & \multicolumn{2}{|c|}{ Contemplation } & \multicolumn{2}{|c|}{ Preparation } & \multicolumn{2}{|c|}{ Action } & \multicolumn{2}{|c|}{ Maintenance } \\
\hline & I & $\mathrm{C}$ & I & $\mathrm{C}$ & I & $\mathrm{C}$ & I & $\mathrm{C}$ & I & $\mathrm{C}$ & I & $\mathrm{C}$ \\
\hline \multicolumn{13}{|l|}{ Intention to change } \\
\hline Fat amount (reduction) & 100 & 95 & 25.0 & 21.1 & 18.0 & 10.5 & 22.0 & 21.1 & 21.0 & 24.2 & 14.0 & 23.2 \\
\hline Type of fat & 100 & 95 & 29.0 & 28.4 & 23.0 & 12.6 & 10.0 & 17.9 & 14.0 & 20.0 & 24.0 & 21.1 \\
\hline Vegetables (increase) & 100 & 95 & 9.0 & 14.7 & 16.0 & 11.2 & 21.0 & 24.2 & 19.0 & 13.7 & 35.0 & 35.8 \\
\hline Pulses (increase) & 100 & 94 & 18.0 & 20.2 & 15.0 & 9.6 & 21.0 & 20.2 & 10.0 & 7.4 & 36.0 & 42.6 \\
\hline Fruit (increase) & 98 & 91 & 17.3 & 19.8 & 11.2 & 6.6 & 17.3 & 24.2 & 11.2 & 11.0 & 42.9 & 38.5 \\
\hline Sugar (reduction) & 100 & 94 & 9.0 & 6.4 & 14.0 & 10.6 & 14.0 & 16.0 & 32.0 & 24.5 & 31.0 & 42.6 \\
\hline White flour (reduction) & 98 & 92 & 25.5 & 20.7 & 17.3 & 9.8 & 12.2 & 17.4 & 20.4 & 17.4 & 24.5 & 34.8 \\
\hline Reduce weight & 100 & 94 & 15.0 & 18.1 & 17.0 & 20.2 & 36.0 & 30.9 & 22.0 & 19.1 & 10.0 & 11.7 \\
\hline
\end{tabular}

Percentage in each stage of change for different indicators of healthier eating and weight reduction, intervention and control group, baseline

$I$ intervention, $C$ control

No significant differences were found between the groups 
Table 3 Distribution into stages of change at follow-up

\begin{tabular}{|c|c|c|c|c|c|c|c|c|c|c|c|c|}
\hline \multirow[b]{2}{*}{ Group } & \multicolumn{2}{|l|}{$N$} & \multicolumn{2}{|c|}{ Precontemplation } & \multicolumn{2}{|c|}{ Contemplation } & \multicolumn{2}{|c|}{ Preparation } & \multicolumn{2}{|c|}{ Action } & \multicolumn{2}{|c|}{ Maintenance } \\
\hline & I & $\mathrm{C}$ & I & $\mathrm{C}$ & I & $\mathrm{C}$ & I & $\mathrm{C}$ & I & $\mathrm{C}$ & I & $\mathrm{C}$ \\
\hline \multicolumn{13}{|l|}{ Intention to change } \\
\hline Fat amount (reduction) & 80 & 73 & 12.5 & 21.9 & 1.3 & $8.2^{\mathrm{a}}$ & 21.3 & 21.9 & 55.0 & $26.0 * *$ & 10.0 & 21.9 \\
\hline Type of fat & 80 & 74 & 13.8 & $35.1 * *$ & 5.0 & $5.4^{\mathrm{a}}$ & 20.0 & 13.5 & 45.0 & $21.6^{* *}$ & 16.3 & 24.3 \\
\hline Vegetables (increase) & 80 & 74 & 5.0 & $17.6^{*}$ & 3.8 & $2.7^{\mathrm{a}}$ & 28.8 & 24.3 & 45.0 & $21.6^{* *}$ & 17.5 & $33.8^{*}$ \\
\hline Pulses (increase) & 80 & 74 & 7.5 & $20.3^{*}$ & 3.8 & $4.1^{\mathrm{a}}$ & 31.3 & 21.6 & 35.0 & $17.6^{*}$ & 22.5 & 36.5 \\
\hline Fruit (increase) & 80 & 72 & 15.0 & 16.7 & 2.5 & $4.2^{\mathrm{a}}$ & 28.8 & 31.9 & 30.0 & 15.3 & 23.8 & 31.9 \\
\hline Sugar (reduction) & 80 & 74 & 3.8 & $14.9 *$ & 0 & $10.8^{\mathrm{a}}$ & 15.0 & 8.1 & 63.8 & $31.1 * *$ & 17.5 & $35.1^{*}$ \\
\hline White flour (reduction) & 80 & 73 & 5.0 & $20.5 * *$ & 0 & $9.6^{\mathrm{a}}$ & 28.8 & 19.2 & 56.3 & $23.3 * *$ & 10.0 & $27.4^{*}$ \\
\hline Reduce weight & 79 & 74 & 11.4 & 8.1 & 7.6 & 10.8 & 39.2 & 41.9 & 30.4 & 23.0 & 11.4 & 16.2 \\
\hline
\end{tabular}

Percentage in each stage of change for different indicators of healthier eating and weight reduction, intervention and control group, follow-up $I$ intervention, $C$ control

* Difference between intervention and control: $P<0.05$, computed by chi-square test

** Difference between intervention and control: $P<0.01$, computed by chi-square test

${ }^{a}$ Chi-square statistics could not be computed due to expected value of $<5$ in more than $20 \%$ of cells in $2 \times 2$ table

Fig. 1 Relationships between participation in group sessions, stages of change and weight loss. Odds ratio $(O R)$ and confidence interval $(C I)$ for being in action stage (action and maintenance) of change for dietary behaviours and weight reduction and for weight loss, according to number of group sessions attended, and OR (CI) for weight loss according to stages of change for dietary behaviours and weight reduction. From age-adjusted logistic regressions. ${ }^{1}$ Ref: preaction stages. ${ }^{2}$ Ref: No change or weight gain

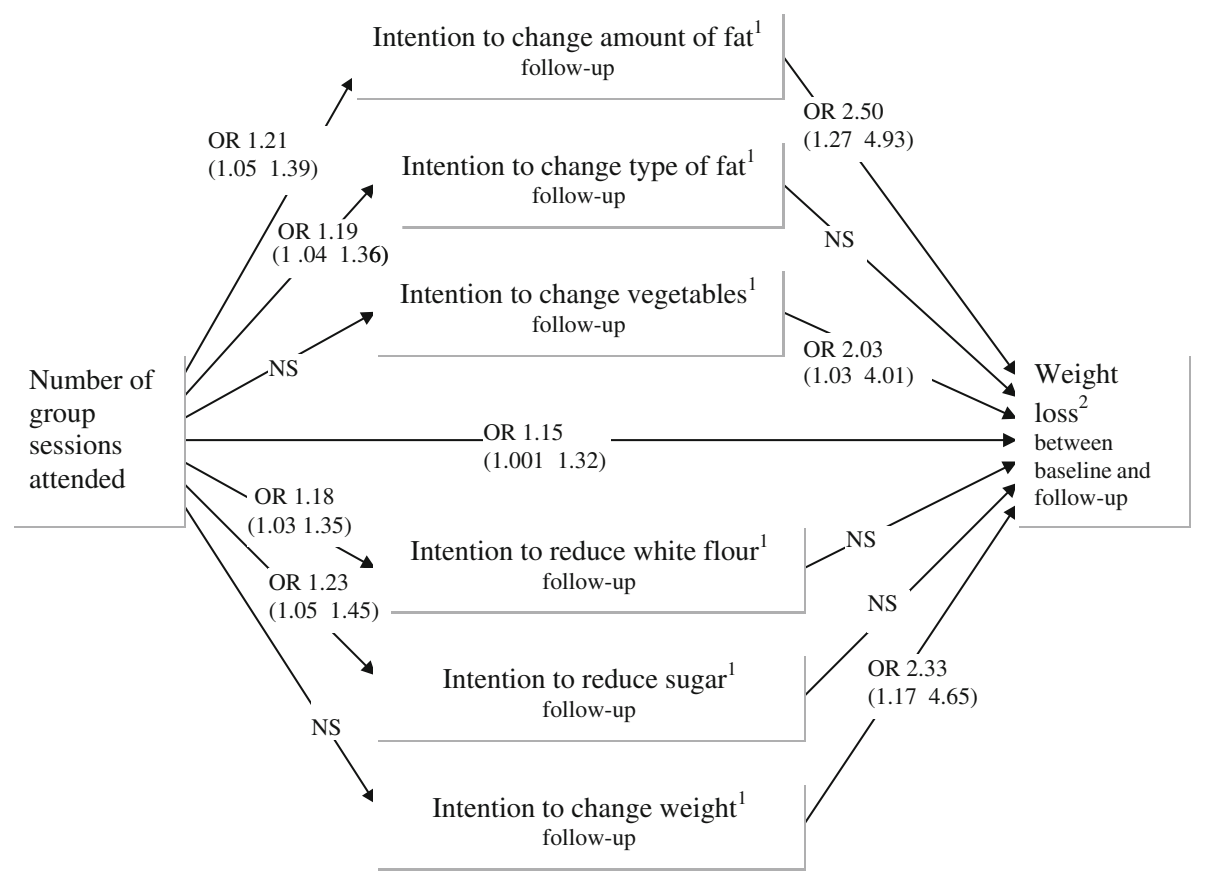

these sessions made the participants more conscious about healthy dietary habits and motivated to start acting according to it. It is possible that the frequent attendees were more inclined to please the interviewers by answering what they had learnt. However, actual dietary changes have previously been reported in the intervention group [26], and the weight reduction associated with number of group sessions attended implies that changes in habits have followed the group sessions. Even if the average weight loss was not large, a modest weight loss, or at least prevention of further weight gain, in a high risk population may have substantial positive effects from a public health perspective. It may be questioned if an intention to lose weight for some women was the motivation for taking part in the intervention. However, the relatively small proportion being in the action stage for reducing weight even at follow-up makes this less likely.

A larger proportion of the control group was in the precontemplation and maintenance stages for several intentions after the intervention. Both have no intention to change behaviour, possibly due to already healthy habits, true or perceived, or because of previous failings in 
changing the given behaviour. It has previously been shown in our sample some regressed from maintenance to action at follow-up, especially for the intervention group [26]. It is likely that the participants after the group sessions have been be more aware that what they have considered to be healthy practise is not necessarily true. They may thereby move from maintenance to action stage, without having an actual relapse in behaviour, but rather due to more knowledge about healthy choices. The impact of change in intentions may vary considerably depending on the stages a person moves from and to. Our results showed that being in action stages for several healthy dietary habits at follow-up were related to weight loss, regardless of stage at baseline.

In previous analyses of the sample, an increasing proportion in the action stages was observed from baseline to follow-up in the intervention group, but not in the control group, with regard to changing amount and type of fat, white flour and sugar [26]. The upward movement through the stages was in agreement with the changes made in intake of foods [26]. The present study showed that intention to change some dietary behaviours and weight were related to having lost weight. These results indicate that the construct of stages of change may be successfully used in following the results from lifestyle interventions among South Asians. More research is needed in order to know whether other constructs of the Trans Theoretical Model, self-efficacy and decisional balance, are suited for studies in South Asian populations.

\section{Limitations of This Study}

The South Asian population may be difficult to recruit, because of low literacy, poor skills in host language, restrictions on meeting health workers of opposite sex and also health beliefs and behaviours different from the host population. The multi-recruitment strategy in this study may have resulted in a sample already above average interested in health and in prevention of diabetes, which may have reduced the difference in change between the groups. This may have given a sample of women more likely to have intention to change dietary habits before the intervention than is the case among Pakistani women in Norway in general. However, there were considerable proportions of women in the pre-action stages at baseline. Thus, both women with and without clear intentions to make lifestyle changes were enrolled in the intervention. Furthermore, the fact that the relationships between the intentions the women had at baseline and attendance in the intervention program were not significant, makes it unlikely that such a biased enrolment have affected the results significantly.
The group sessions were aimed at equipping the women to make healthy lifestyle changes in their everyday life, and the proportion of women reporting to be in action stages to make healthy dietary changes increased after the intervention. Nevertheless, their circumstances were not changed. Social obligations, such as serving sweets and foods rich in fat to guests, and catering to other family members ${ }^{\text {* }}$ wishes, which have previously been reported as important barriers to healthy dietary changes among Pakistani immigrant women [28], will still be present. Furthermore, the intervention did not include attempts to change the environment, such as availability or accessibility to healthful foods. Future interventions might improve their impact by including more family members, also focusing on a health promoting environment and making efforts to increase the availability of healthy options that are feasible to purchase convenient and economically in the local community.

\section{New Contributions to the Literature}

Participation in a culturally adapted intervention among Pakistani immigrant women was related to an upward move into action stages of healthy dietary behaviours, which increased the likelihood of weight loss. Further research is needed to explore the barriers to moving on to action stages of healthy behaviours in this population.

Acknowledgments MW and GHO planned and supervised the project. BB and VTH conducted the intervention and coordinated data collection. MKRK did the statistical analyses and the drafting of the article. All authors contributed in the final stage of the writing, and approved the final manuscript. We want to thank Monica Morris, Aisha Ali, Anica Munir, Marianne Lunde and Eva Kristensen for their contribution in coordination and collection of data. We also want to thank all the participating women who gave us of their time and shared their knowledge and experiences with us. This work was supported by the Norwegian Research Council [166977/v50]; the Throne Holst foundation [2875] and the Jahre Foundation. Reebok was sponsoring footwear to all the participants of the study.

Open Access This article is distributed under the terms of the Creative Commons Attribution Noncommercial License which permits any noncommercial use, distribution, and reproduction in any medium, provided the original author(s) and source are credited.

\section{References}

1. Kumar BN, Meyer HE, Wandel M, Dalen I, Holmboe-Ottesen G. Ethnic differences in obesity among immigrants from developing countries, in Oslo, Norway. Int J Obes (Lond). 2006;30(4): 684-90.

2. Jenum AK, Holme I, Graff-Iversen S, Birkeland KI. Ethnicity and sex are strong determinants of diabetes in an urban Western 
society: implications for prevention. Diabetologia. 2005;48(3): 435-9.

3. Abate N, Chandalia M. Ethnicity and type 2 diabetes: focus on Asian Indians. J Diabetes Complications. 2001;15(6):320-7.

4. Cappuccio FP, Cook DG, Atkinson RW, Strazzullo P. Prevalence, detection, and management of cardiovascular risk factors in different ethnic groups in south London. Heart. 1997;78(6): 555-63.

5. Anand SS, Yusuf S, Vuksan V, Devanesen S, Teo KK, Montague PA, Kelemen L, Yi C, Lonn E, Gerstein H, Hegele RA, McQueen $\mathrm{M}$. Differences in risk factors, atherosclerosis, and cardiovascular disease between ethnic groups in Canada: the Study of Health Assessment and Risk in Ethnic groups (SHARE). Lancet. 2000; 356(9226):279-84.

6. Bogers RP, Bemelmans WJ, Hoogenveen RT, Boshuizen HC, Woodward M, Knekt P, van Dam RM, Hu FB, Visscher TL, Menotti A, Thorpe RJ Jr, Jamrozik K, Calling S, Strand BH, Shipley MJ. Association of overweight with increased risk of coronary heart disease partly independent of blood pressure and cholesterol levels: a meta-analysis of 21 cohort studies including more than 300,000 persons. Arch Intern Med. 2007;167(16): 1720-8.

7. Hussain A, Claussen B, Ramachandran A, Williams R. Prevention of type 2 diabetes: a review. Diabetes Res Clin Pract. 2007; 76(3):317-26.

8. Himmelgreen DA, Perez-Escamilla R, Martinez D, Bretnall A, Eells B, Peng Y, Bermudez A. The longer you stay, the bigger you get: length of time and language use in the U.S. are associated with obesity in Puerto Rican women. Am J Phys Anthropol. 2004;125(1):90-6.

9. Goel MS, McCarthy EP, Phillips RS, Wee CC. Obesity among US immigrant subgroups by duration of residence. JAMA. 2004;292(23):2860-7.

10. Kaplan MS, Huguet N, Newsom JT, McFarland BH. The association between length of residence and obesity among Hispanic immigrants. Am J Prev Med. 2004;27(4):323-6.

11. Neuhouser ML, Thompson B, Coronado GD, Solomon CC. Higher fat intake and lower fruit and vegetables intakes are associated with greater acculturation among Mexicans living in Washington State. J Am Diet Assoc. 2004;104(1):51-7.

12. Kelleher CC, Lynch JW, Daly L, Harper S, Fitz-Simon N, Bimpeh Y, Daly E, Ulmer H. The "Americanisation" of migrants: evidence for the contribution of ethnicity, social deprivation, lifestyle and life-course processes to the mid-20th century Coronary Heart Disease epidemic in the US. Soc Sci Med. 2006;63(2):465-84.

13. Mellin-Olsen T. Veileder for helsepersonell om helse-og kostrådgivning til innvandrere [Guide for health personnel about health — and dietary advice to immigrants]. Oslo: Statens ernæringsråd; 1998.

14. Whittemore R. Culturally competent interventions for Hispanic adults with type 2 diabetes: a systematic review. J Transcult Nurs. 2007;18(2):157-66.

15. O'hare JP, Raymond NT, Mughal S, Dodd L, Hanif W, Ahmad Y, Mishra K, Jones A, Kumar S, Szczepura A, Hillhouse EW, Barnett AH. Evaluation of delivery of enhanced diabetes care to patients of South Asian ethnicity: the United Kingdom Asian Diabetes Study (UKADS). Diabet Med. 2004;21(12):1357-65.

16. Baradaran HR, Knill-Jones RP, Wallia S, Rodgers A. A controlled trial of the effectiveness of a diabetes education programme in a multi-ethnic community in Glasgow [ISRCTN28317455]. BMC Public Health. 2006;6:134.

17. Hawthorne K. Effect of culturally appropriate health education on glycaemic control and knowledge of diabetes in British Pakistani women with type 2 diabetes mellitus. Health Educ Res. 2001;16(3): 373-81.
18. Kousar R, Burns C, Lewandowski P. A culturally appropriate diet and lifestyle intervention can successfully treat the components of metabolic syndrome in female Pakistani immigrants residing in Melbourne, Australia. Metabolism. 2008;57(11):1502-8.

19. Mathews R, Lewandowski P. Coronary heart disease in South Asian immigrants: synthesis of research and implications for health promotion and prevention in nursing practice. J Transcult Nurs. 2008;19(3):292-9.

20. Prochaska JO, Redding CA, Evers KE. The transtheoretical model and stages of change. In: Lewis FM, Glanz K, Rimer BK, editors. Health behavior and health education: theory, research, and practice. San Francisco, CA: Jossey-Bass; 2002. p. 99-120.

21. Greene GW, Rossi SR, Rossi JS, Velicer WF, Fava JL, Prochaska JO. Dietary applications of the stages of change model. J Am Diet Assoc. 1999;99(6):673-8.

22. Di NJ, Schinke SP, Prochaska JO, Contento IR. Application of the transtheoretical model to fruit and vegetable consumption among economically disadvantaged African-American adolescents: preliminary findings. Am J Health Promot. 2006;20(5):342-8.

23. Vallis M, Ruggiero L, Greene G, Jones H, Zinman B, Rossi S, Edwards L, Rossi JS, Prochaska JO. Stages of change for healthy eating in diabetes: relation to demographic, eating-related, health care utilization, and psychosocial factors. Diabetes Care. 2003;26(5):1468-74.

24. De Vet E, De Nooijer J, de Vries NK, Brug J. The transtheoretical model for fruit, vegetable and fish consumption: associations between intakes, stages of change and stage transition determinants. Int J Behav Nutr Phys Act. 2006;3:13.

25. Mathews G, Alexander J, Rahemtulla T, Bhopal R. Impact of a cardiovascular risk control project for South Asians (Khush Dil) on motivation, behaviour, obesity, blood pressure and lipids. J Public Health (Oxf). 2007;29(4):388-97.

26. Johansen KS, Bjørge B, Hjellset VT, Holmboe-Ottesen G, Raberg M, Wandel M. Changes in food habits and motivation for healthy eating among Pakistani immigrant women in Oslo. Results from the InnvaDiab-DEPLAN study. Public Health Nutr. 2009;13(6):858-67.

27. Hussain-Gambles M, Leese B, Atkin K, Brown J, Mason S, Tovey P. Involving South Asian patients in clinical trials. Health Technol Assess. 2004;8(42):iii 1- 109.

28. Mellin-Olsen T, Wandel M. Changes in food habits among Pakistani immigrant women in Oslo, Norway. Ethn Health. 2005; 10(4):311-39.

29. Lorentzen C, Ommundsen Y, Jenum AK, Holme I. The "Romsas in Motion" community intervention: program exposure and psychosocial mediated relationships to change in stages of change in physical activity. Int J Behav Nutr Phys Act. 2007;4:15.

30. Kumar B, Meyer HE: The Oslo immigrant study-methods. 2003. http://www.fhi.no/dav/906123CAA9.pdf. Accessed 22 Sep 2009.

31. Schwarz PE, Lindstrom J, Kissimova-Scarbeck K, Szybinski Z, Barengo NC, Peltonen M, Tuomilehto J. The European perspective of type 2 diabetes prevention: diabetes in Europe-prevention using lifestyle, physical activity and nutritional intervention (DE-PLAN) project. Exp Clin Endocrinol Diabetes. 2008;116(3): 167-72.

32. HO W. Appropriate body-mass index for Asian populations and its implications for policy and intervention strategies. Lancet. 2004;363(9403):157-63.

33. World Health Organization, International Diabetes Federation. Definition and diagnosis of diabetes mellitus and intermediate hyperglycemia. Report of a WHO/IDF consultation. Geneva: World Health Organization; 2006.

34. Norris SL, Zhang X, Avenell A, Gregg E, Bowman B, Serdula M, Brown TJ, Schmid $\mathrm{CH}$, Lau J. Long-term effectiveness of 
lifestyle and behavioral weight loss interventions in adults with type 2 diabetes: a meta-analysis. Am J Med. 2004;117(10): 762-74.

35. Kristal AR, Glanz K, Tilley BC, Li S. Mediating factors in dietary change: understanding the impact of a worksite nutrition intervention. Health Educ Behav. 2000;27(1):112-25.
36. Glanz K, Patterson RE, Kristal AR, Feng Z, Linnan L, Heimendinger J, Hebert JR. Impact of work site health promotion on stages of dietary change: the working well trial. Health Educ Behav. 1998;25(4):448-63. 